\title{
Claims-based proxies of patient instability among commercially insured adults with schizophrenia
}

This article was published in the following Dove Press journal:

ClinicoEconomics and Outcomes Research

\author{
Charles Ruetsch' \\ Hyong Un ${ }^{2}$ \\ Heidi C Waters ${ }^{3}$ \\ 'Health Analytics, LLC, Columbia, MD, \\ USA; ${ }^{2}$ Aetna, Inc, Blue Bell, PA, USA; \\ ${ }^{3}$ Otsuka Pharmaceutical Development \\ \& Commercialization, Inc., Princeton, \\ NJ, USA
}

\begin{abstract}
Objective: Schizophrenia (Sz) patients are among the highest utilizers of hospital-based services. Prevention of relapse is in part a treatment goal in order to reduce hospital admissions. However, predicting relapse is a challenge, particularly for payers and disease management firms with only access to claims data. Understandably, such organizations have had little success predicting relapse. A tool that allows payers to identify patients at elevated risk of relapse could facilitate targeted interventions prior to relapse and avoid rehospitalization. In this study, a series of proxy measures of patient instability, calculated from claims data were examined for their utility in identifying Sz patients at elevated risk of relapse.
\end{abstract}

Methods: Aetna claims were used to assess the relationship between instability of Sz patients and valence and magnitude of antipsychotic (AP) medication change during a 2-year period. Six proxies of instability including hospital admissions, emergency department visits, medication utilization patterns, and use of outpatient services were identified. Results were replicated using claims data from Truven MarketScan ${ }^{\circledR}$.

Results: Patients who switched AP ingredient had the highest overall instability at the point of switch and the second steepest decline in instability following switch. Those who changed to a long-acting injectable AP showed the second highest level of instability and the steepest decrease in instability following the change. Patients augmented with a second AP showed the smallest increase in instability, up to the switch. Results were directionally consistent between the two data sets.

Conclusion: Using claims-based proxy measures to estimate instability may provide a viable method to better understand Sz patient markers of change in disease severity. Also, such proxies could be used to identify those individuals with the greatest need for treatment modification preventing relapse, improving patient outcomes, and reducing the burden of illness.

Keywords: schizophrenia, relapse, algorithm, claims data

\section{Key points}

1. What is already known about the topic?

- Health plans and other payers have limited tools to identify patients with schizophrenia at elevated risk of relapse.

- Claims-based proxies or predictors of relapse, including medication adherence, and psychiatric hospitalization, are the best predictors available to payers, but have poor positive predictive power.

2. What does the paper add to existing knowledge?

- Consistent with defining schizophrenia as a syndrome, use of a single variable is not always sufficient to predict relapse.
Health Analytics, LLC, 9200 Rumsey

Road, Suite 215, Columbia, MD 21045 ,

USA

$\mathrm{Tel}+\mathrm{I} 4109973314$

Fax + I 4109974545

Email cruetsch@healthanalytic.com 
- A new method for identifying instability in patients with schizophrenia based on six claims-based proxies is presented.

3. What insights does the paper provide for informing health care-related decision-making?

- This study demonstrates that claims-based proxies of patient instability may be useful in assessment of patients with schizophrenia who may benefit from treatment modification.

\section{Introduction}

Schizophrenia $(\mathrm{Sz})$ is a chronic mental illness that emerges in late adolescence through early adulthood, affects approximately $1 \%$ of the population, and is characterized by psychosis, cognitive impairment, flat affect, and social withdrawal. ${ }^{1,2}$ The presentation of Sz can be heterogeneous, which has led researchers and clinicians to postulate that it may be a clinical syndrome comprised of various patterns of symptom expression as opposed to a single disease. ${ }^{3,4}$ Patients with $\mathrm{Sz}$ often cycle through symptom remission, exacerbation, relapse, and potentially hospitalization. Relapse averages between $20 \%$ and $40 \%$ per year depending upon many factors including treatment, date of initial diagnosis, calculation methodology, and population..$^{5-13}$ Relapse typically starts with prodromal symptoms including changes in cognition, affect, physical and social functioning, beliefs, and/or behavior. ${ }^{14-19}$ If $\mathrm{Sz}$ symptom expression is idiosyncratic as postulated, then prediction of relapse based on any single prodromal symptom would fail because of lack of sensitivity.

\section{Cost of schizophrenia}

Annual costs attributable to $\mathrm{Sz}$ in the United States were estimated at $\$ 37.7$ billion for direct medical costs and an additional $\$ 117$ billion for indirect costs. ${ }^{20}$ Patients with $\mathrm{Sz}$ who relapse cost up to five-fold more than those who do not. ${ }^{21-23}$ The major cost of treating $\mathrm{Sz}$ is hospital-based care following relapse. ${ }^{24}$ Therefore, improving methods that identify patients at greatest risk of imminent relapse may reduce relapse and the use of associated high cost services.

\section{Patient instability}

Due to the heterogeneity of relapse precursors, individual prodromal symptoms have little ability to predict change in inpatient status (eg, relapse, change in treatment approach) within a population of $\mathrm{Sz}$ patients with sufficient sensitivity and positive predictive power for use in case finding. ${ }^{25-27}$ Drivers of patient decompensation have been well researched, ${ }^{28}$ but have little practical application, leaving payers with few tools to manage $\mathrm{Sz}$ patient health care costs. ${ }^{13}$ There is some support for employing antipsychotic (AP) medication noncompliance, emergency department (ED) utilization, disease duration, and other claims-based metrics to identify potentially impending relapse, but greater sensitivity is needed for disease management case finding purposes. ${ }^{10,22,29}$ Low positive predictive power could be a result of heterogeneity of $\mathrm{Sz}$ patient populations. For example, AP medication noncompliance predicts relapse in some patients. ED utilization is also related to relapse in perhaps some of the same patients, as well as others. Perhaps it is the heterogeneity among Sz patients that results in relapse predictors' lack of strong agreement with relapse. It could be that the predictors work very well for specific subgroups of patients. In this scenario, a group of predictors that allows for idiosyncratic calculation of relapse risk would potentially predict a larger number of patients' relapse. Based on the abovementioned, multiple manifest indicators (eg, ED utilization, medication compliance) that have clear conceptual and theoretical links to an unmeasured dimension (eg, relapse risk) can help prediction with greater accuracy and less error than any one indicator, including individual symptoms predicting psychiatric decompensation. ${ }^{25,30}$ Were such a composite measure, calculated from administrative claims data, able to predict relapse among a large number of $\mathrm{Sz}$ patients with agreement statistics superior to single indicators (eg, ED utilization or medication compliance), it could be of value to health plans struggling to manage care of Sz patients with greater effectiveness. To our knowledge, no such indicator has been systematically studied within a plans' administrative claims data set.

This study explored the utility of multiple administrative claims-based markers of patient instability, called patient instability events (PIEs), organized into idiosyncratic arrays, to track change in patient stability over time. As providers often respond to patient decompensation with treatment adjustment, the relationship between patient instability and change in treatment regimen was explored. The positive association between patient instability as measured by the PIE summary score and treatment regimen change may provide some support for using the PIE summary score as a relapse risk case finding algorithm.

\section{Methods}

Data from two sources were used for this study. First, administrative claims data of patients with diagnosis of $\mathrm{Sz}$ 
from Aetna's health maintenance organization commercial membership for the period from January 1, 2010 to September 30, 2014 were extracted, including medication history, diagnosis, and service utilization. Patient trajectory prior to and following a change in treatment regimen was evaluated. The second data source used was Truven MarketScan ${ }^{\circledR}$ (Truven Health Analytics, Inc., Ann Arbor, MI, USA) commercial claims data from 2010 to 2013 for patients with $\mathrm{Sz}$, from which similar data fields were extracted. Identical analyses were used to confirm the relationship between patient instability and changes in psychiatric medication regimens. The claims data donated by Aetna for this study were freely available to Health Analytics for the purposes of this research. Truven MarketScan ${ }^{\circledR}$ commercial claims data were licensed by Otsuka America from Truven for the purposes of this study. No institutional review board oversight was required as no protected health information was included in either data set nor was there any risk to patient safety or privacy.

\section{Patient eligibility}

Patients aged 18 or older with a diagnosis of $\mathrm{Sz}$, as identified by one inpatient or two outpatient claims with an International Classification of Diseases, Ninth Edition, Clinical Modification (ICD-9-CM) code of 295.xx within a 1-year period were identified. The earliest appearance of hospitalization for $\mathrm{Sz}$ or the first of two outpatient visits for Sz within a 1-year period was designated as the study index date and used as the first day of the study measurement period. Patients were required to have at least 2 years of continuous eligibility, allowing for a 30-day gap. Analyses excluded patients with a diagnosis of schizophreniform (ICD-9-CM 295.4) or schizoaffective (ICD-9-CM 295.7) disorders in the absence of the other $\mathrm{Sz}$ diagnoses. As a result of the inclusion and exclusion criteria, this study had a final sample size of $n=392$ for Aetna and $\mathrm{n}=5,589$ for Truven.

\section{Study grouping}

Patients were grouped hierarchically into one of four treatment cohorts based on pattern of AP prescription fills during the 2-year study period (Table 1). For long-acting injectable (LAI) AP fills, both pharmacy and medical record J-codes were used; National Drug Code codes within pharmacy claims were used to assess oral AP prescribing. In addition to the study index date, each patient was assigned a treatment index date used to demarcate the pre- and postperiods for patient follow-up. The treatment index date is the date of the event that defined group assignment (Table 1). For example, the treatment index date for cases in the LAI group is the date of first appearance of the LAI following the study index date.

\section{PIEs}

Six proxy measures of instability, termed PIEs, were identified and/or computed using administrative claims. Each PIE represented an event that may be related to or precede a potential relapse (Table 2). All PIEs were calculated for each of eight 90-day periods (quarter), four in the pretreatment index period and four in the posttreatment index period. The quarterly PIE summary score was obtained by summing the six PIEs using unit weighting for each of the eight quarters within the measurement period.

PIE scores for all patients within each medication group were averaged within each quarter and used as a basis of comparison among the four study groups. Comparisons were made between groups' PIE summary score, as well as each of the six individual PIEs. Individual and summary score PIEs were presented for each pre- and posttreatment index quarter and the total pre- and posttreatment periods. Individual PIEs

Table I Study group definition

\begin{tabular}{|c|c|c|}
\hline Study group & Definition & Treatment index date \\
\hline LAI & $\begin{array}{l}\text { Evidence of } L A I \text { use through a fill in the pharmacy } \\
\text { record or a J-code for an LAI injection in the medical } \\
\text { record }\end{array}$ & $\begin{array}{l}\text { First use of an LAI in the claims data. The LAI fill may appear in the } \\
\text { pharmacy table or as a J-code in the medical table for an LAI injection; the } \\
\text { first LAl event qualifies as the LAI group index date }\end{array}$ \\
\hline Polypharmacy & $\begin{array}{l}\text { Evidence of multiple AP ingredients in the pharmacy } \\
\text { record which were used concurrently for a period of } \\
60 \text { days or greater }\end{array}$ & $\begin{array}{l}\text { First fill for a second AP ingredient on record that overlaps for a period of } \\
\geq 60 \text { days with the previous AP ingredient on record }\end{array}$ \\
\hline Switch & $\begin{array}{l}\text { Evidence of multiple different AP ingredients in } \\
\text { the pharmacy record prescribed independently } \\
\text { (medication overlap }<60 \text { days) }\end{array}$ & $\begin{array}{l}\text { First fill for a second AP ingredient on record that was part of a minimum } \\
\text { of a } 90 \text { days' supply. Overlap of the two medications (the original ingredient } \\
\text { and the new ingredient) was } \geq 60 \text { days to allow for transition of treatment }{ }^{37}\end{array}$ \\
\hline Monotherapy & $\begin{array}{l}\text { Evidence of only a single AP ingredient in the } \\
\text { pharmacy record }\end{array}$ & $\begin{array}{l}\text { Earliest antipsychotic fill after the study index date that was part of a } \\
\text { minimum of a } 90 \text { days' supply of a single ingredient antipsychotic }\end{array}$ \\
\hline
\end{tabular}

Abbreviations: AP, antipsychotic; LAl, long-acting injectable. 
Table 2 PIEs

\begin{tabular}{|c|c|c|}
\hline PIE & Indicator type & Definition \\
\hline Low AP medication PDC & Dichotomous & $\mathrm{PDC} \geq 0.8=0, \mathrm{PDC}<0.8=\mathrm{I}$ \\
\hline $\begin{array}{l}\text { Sz-related inpatient } \\
\text { hospitalizations }\end{array}$ & Continuous & Each inpatient hospitalization on a claim record with a diagnosis of $\mathrm{Sz}(295 . x \mathrm{x})=\mathrm{I}$ \\
\hline Psychiatric ED visit & Continuous & $\begin{array}{l}\text { Each ED visit on a claim with a psychiatric diagnosis (schizophrenia } 295 . x x \text {, affective psychoses } \\
296 . x x \text {, anxiety disorders } 300 . x x \text {, personality disorders } 301 . x x \text {, sexual deviations } 302 . x x \text {, alcohol } \\
\text { dependence } 303 . x x \text {, drug dependence } 304 . x x \text {, and nondependent abuse of drugs } 305 . x x \text { ) }=1\end{array}$ \\
\hline $\begin{array}{l}\text { Other psychiatric } \\
\text { medications }\end{array}$ & Dichotomous & Use of other psychiatric medications $=I$ \\
\hline Other psychotic behaviors & Dichotomous & Presence of other psychotic behaviors $=\mathrm{I}$ \\
\hline $\begin{array}{l}\text { Decrease in outpatient } \\
\text { office visits }\end{array}$ & Dichotomous & $>50 \%$ decrease in office visits $=I$ \\
\hline
\end{tabular}

Abbreviations: AP, antipsychotic; ED, emergency department; PDC, proportion of days covered; PIE, patient instability event; Sz, schizophrenia.

and the PIE summary scores for all time periods were tested for between-groups and within-group differences over time as well as the interaction of the between group factor and time.

A relative time scale based on the treatment index date was used for this analysis, with the treatment index date set as time 0 , with four pre-period quarters (quarter -3 to 0 ) prior to the treatment index date, and four postperiod quarters (quarter 1-4) following the treatment index date. This approach resulted in some members not having complete preor postperiods due to the timing of the treatment index date. Therefore, each quarter is composed of a unique population of members. In general, the pre-period quarters had smaller sample sizes compared to the postperiod quarters.

\section{Analyses}

Descriptive statistics were reported for all demographic measures by study group and for the total study sample for both the Aetna and Truven data. For the PIE summary score and individual PIE measures, means and standard deviations were reported. Differences between study groups on means were tested using one-way analysis of variance and on frequencies using $\chi^{2}$ test of proportions. Repeated-measures general linear model was used to calculate between- and within-group differences (across quarters). Between and within interaction terms were also tested for the PIE summary score during the entire measurement period as well as during the postperiod within the Aetna sample. Pairwise comparisons were performed post hoc to assess direction and strength of specific relationships within significant terms. All data management, descriptive, and bivariate analyses were conducted using SPSS v.20 (IBM Corporation, Armonk, NY, USA), while multivariate analyses were conducted using STATA v.13 (StataCorp LP, College Station, TX, USA).

\section{Results}

When grouped according to medication use, members within the Aetna dataset were assigned to the monotherapy $(n=229)$, switch $(n=81)$, polypharmacy $(n=57)$, and LAI $(n=25)$ cohorts. Males were over-represented in the LAI group (76\%), whereas a more even gender distribution existed among the other three groups. The LAI group was the youngest (mean age $=35.2$ years) and the monotherapy group oldest (mean age $=45.4$ years) at study index. The majority of patients were the primary insurance subscriber (51.8\%) followed by children and spouses (25.3\% and $22.4 \%$, respectively).

During the pretreatment index period, the switch group exhibited the highest PIE summary score (8.16), as well as the highest individual PIEs for other psychiatric medications and low AP proportion of days covered (PDC) compared to the other three groups. Conversely, the monotherapy group had the lowest PIE summary score (4.68) and the lowest values for inpatient hospitalization, other psychotic behaviors, and low AP PDC. The polypharmacy group had the lowest individual PIE scores for ED visits and change in outpatient visits and did not have the highest PIE score for any component. The LAI group had the highest PIE scores for inpatient hospitalization, ED visits, and other psychotic behaviors, and the lowest PIE for other psychiatric medications compared to the other groups (Table 3 ).

During the post period there was an increase in PIE summary scores compared to the pre-period for all medication cohorts. The polypharmacy group exhibited the lowest PIE summary score (5.88) followed by the monotherapy, LAI, and switch groups, respectively. The switch group maintained the highest mean PIE summary score (8.81), and also had the highest PIEs for ED visits and change in outpatient 
Table 3 Pre- and posttreatment index period PIEs (Aetna data)

\begin{tabular}{|c|c|c|c|c|c|c|c|c|}
\hline \multirow[t]{2}{*}{ PIE } & \multicolumn{2}{|c|}{ Monotherapy } & \multicolumn{2}{|l|}{ Switch } & \multicolumn{2}{|c|}{ Polypharmacy } & \multicolumn{2}{|l|}{ LAI } \\
\hline & $\begin{array}{l}\text { Pre } \\
(n=28)\end{array}$ & $\begin{array}{l}\text { Post } \\
(n=229)\end{array}$ & $\begin{array}{l}\text { Pre } \\
(n=73)\end{array}$ & $\begin{array}{l}\text { Post } \\
(n=8 I)\end{array}$ & $\begin{array}{l}\text { Pre } \\
(n=25)\end{array}$ & $\begin{array}{l}\text { Post } \\
(n=57)\end{array}$ & $\begin{array}{l}\text { Pre } \\
(n=I I)\end{array}$ & $\begin{array}{l}\text { Post } \\
(n=25)\end{array}$ \\
\hline Low AP PDC, mean (SD) & $0.46(1.20)$ & $1.88(1.37)$ & $2.04(1.35)$ & $1.86(1.33)$ & $1.36(0.99)$ & $0.56(0.82)$ & $1.27(1.19)$ & $1.76(1.36)$ \\
\hline $\begin{array}{l}\text { Sz-related inpatient } \\
\text { hospitalization, mean (SD) }\end{array}$ & $0.21(0.63)$ & $0.21(0.55)$ & $0.22(0.58)$ & $0.44(1.00)$ & $0.48(0.92)$ & $0.35(0.8 I)$ & $1.36(1.75)$ & $0.76(1.09)$ \\
\hline Psychiatric ED visit, mean (SD) & $0.39(1.07)$ & $0.34(1.07)$ & $0.56(1.14)$ & I.0I (I.45) & $0.16(0.37)$ & $0.42(1.15)$ & $0.91(1.04)$ & $0.60(0.91)$ \\
\hline $\begin{array}{l}\text { Other psychiatric medications, } \\
\text { mean (SD) }\end{array}$ & $1.14(1.53)$ & $1.92(1.80)$ & $1.85(1.53)$ & $2.01(1.48)$ & $1.48(1.36)$ & $2.46(1.76)$ & $0.73(1.42)$ & $1.60(1.63)$ \\
\hline $\begin{array}{l}\text { Other psychotic behaviors, } \\
\text { mean (SD) }\end{array}$ & $0.64(1.03)$ & $0.86(1.40)$ & $1.36(1.4 \mathrm{I})$ & $1.36(1.34)$ & $1.08(1.19)$ & $0.74(1.16)$ & $1.55(1.37)$ & $1.52(1.33)$ \\
\hline $\begin{array}{l}\text { Decrease in outpatient visits, } \\
\text { mean (SD) }\end{array}$ & $1.82(1.56)$ & $\mathrm{I} .84(\mathrm{I} .68)$ & $2.14(1.53)$ & $2.12(1.58)$ & $1.20(1.53)$ & $1.35(\mathrm{I} .54)$ & $\mathrm{I} .64(\mathrm{I} .63)$ & $\mathrm{I} .44(\mathrm{I} .6 \mathrm{I})$ \\
\hline PIE summary score, mean (SD) & $4.68(4.47)$ & $7.05(4.42)$ & $8.16(4.08)$ & $8.81(4.21)$ & $5.76(3.54)$ & $5.88(3.84)$ & $7.45(5.37)$ & $7.68(4.11)$ \\
\hline
\end{tabular}

Abbreviations: AP, antipsychotic; ED, emergency department; LAI, long-acting injectable; PDC, proportion of days covered; PIE, patient instability event; Sz, schizophrenia.

visits in the post period. The polypharmacy group had the lowest individual PIE scores for other psychotic behaviors and low AP PDC but the highest PIE for other psychiatric medications. The LAI group had the highest PIEs for inpatient hospitalization and other psychotic behaviors, as was true in the pre-period. However, the inpatient hospitalization PIE decreased by $44 \%$ between the pre- and postperiods. The monotherapy group had the lowest PIE score for inpatient hospitalizations and ED visits (Table 3).

Average total pre- and post-period PIE summary scores were graphed for all eight quarters for the Aetna sample. The monotherapy cohort's postperiod PIE summary score was used as the benchmark for the eight quarters (represented by the black dotted line in Figure 1A). As each members' treatment index date was aligned to fall between quarter 0 and 1 (Figure 1A, gray box), the pre-period is represented by quarters -3 to 0 and the postperiod is represented by quarters $1-4$. Each member's quarters were calculated in relation to their treatment index date. Results from a repeated-measures general linear model confirmed a significant group effect and time effect $(p<0.001)$ on the total number of PIEs, and a trend for a group $\times$ time interaction effect $(p=0.06)$ during the postperiod, with the LAI group's instability declining more rapidly over time compared to the switch and the polypharmacy groups. Pairwise comparisons between overall postperiod PIEs revealed that the LAI and switch groups showed greater instability than the polypharmacy and monotherapy groups $(p<0.05)$.

An analysis of Truven MarketScan ${ }^{\circledR}$ data using the same methodology returned similar results $(p<0.0001)$ (Figure 1B). The switch and LAI groups had the highest quarterly PIE summary scores across the study period in both datasets $(p<0.0001)$. Within Aetna's membership, the switch group had the highest quarterly PIE summary score for the study, while the LAI group had the highest PIE summary score in the Truven database $(p<0.0001)$. The polypharmacy group followed a slightly different trend within both datasets, exhibited by lower PIE summary scores across most of the study period (Figure 1B, gray line); within the Aetna dataset, the polypharmacy group fell below the benchmark in the postperiod. Although the two samples showed a slightly different trajectory across the pre- and postperiods, the highest PIE summary score occurred near the treatment index date between quarters -1 and 1 within both samples.

Within the Aetna sample, there was a decrease in PIE summary score for all groups during the postperiod. The change in individual PIEs over the postperiod was assessed to determine the contribution of specific PIEs to overall change in instability (Figure 2). Individual PIEs for most groups decreased during the postperiod, except for change in outpatient visits for all groups, and inpatient hospitalization and low AP PDC for the polypharmacy group. The LAI group had the largest reduction across the four groups for inpatient hospitalization, ED visits, and other psychotic behaviors. The switch group also had large decreases for ED visits and other psychotic behaviors. The polypharmacy and monotherapy groups exhibited more modest changes in the postperiod. For the polypharmacy group, the largest change was an increase in change in outpatient visits; for the monotherapy group, it was a decrease in low AP PDC (Figure 2).

\section{Discussion}

Health plans have few tools to measure and track instability among patients with Sz. One model available to payers is to estimate trajectory to relapse using claims-based indicators 
A

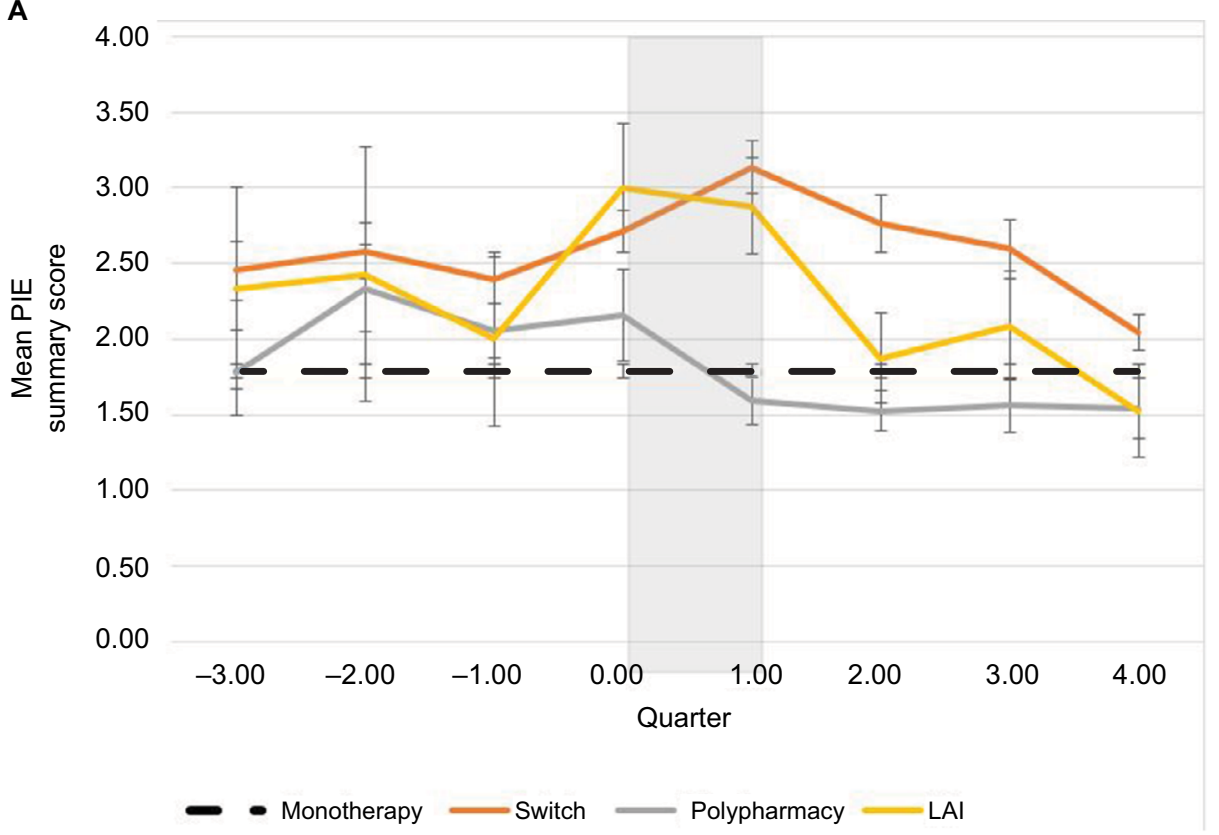

B

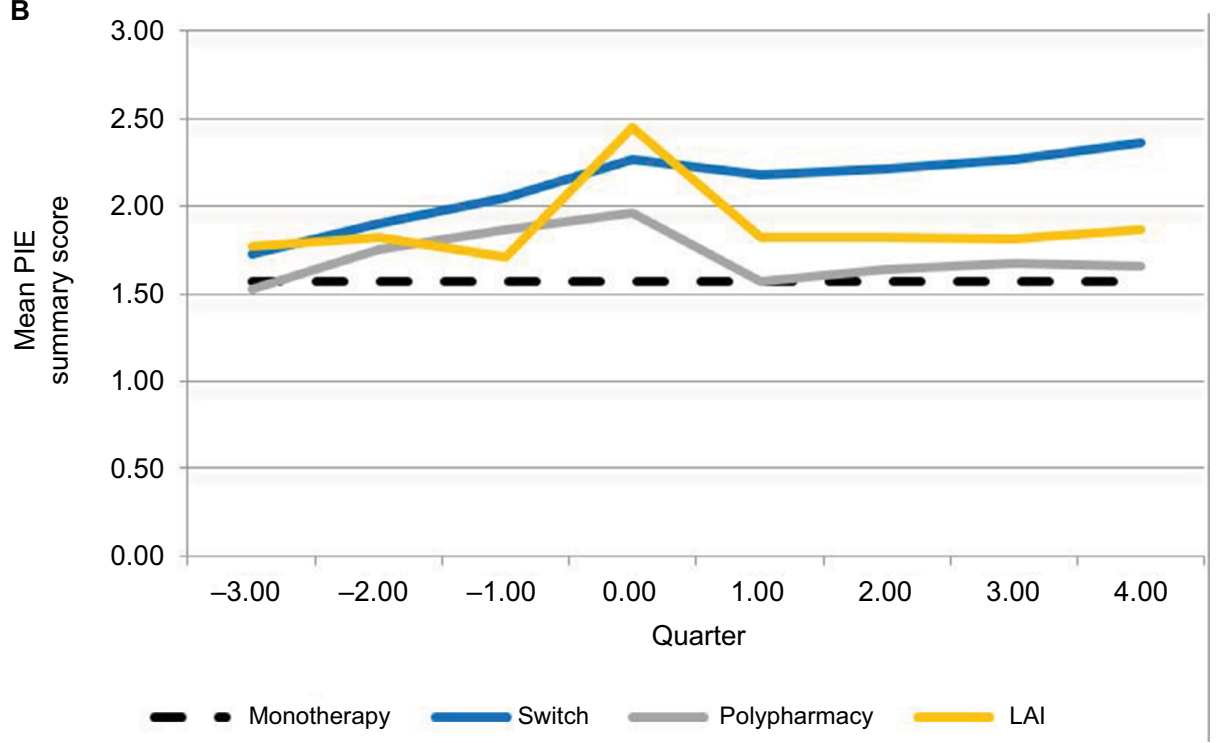

Figure I (A) Group mean PIE scores - Aetna sample, (B) group mean PIE scores - Truven MarketScan ${ }^{\circledR}$ (Truven Health Analytics, Inc., Ann Arbor, MI, USA) sample. Notes: All treatment index dates fall between quarters 0 and I. The dashed black line presented for the monotherapy group represents the average total PIE score across the study postperiod.

Abbreviation: LAI, long-acting injectable; PIE, patient instability event.

such as AP medication adherence or prior psychiatric hospitalization. However, neither of these is effective as a standalone predictor. ${ }^{25}$ By contrast, the current model employed a combination of six claims-based proxy measures of instability (PIEs) that, when summed using unit weighting into a composite score, predicted decompensation with more accuracy than any single measure alone. Rather than use a linear combination of constituent items, the PIE summary score allowed for idiosyncratic combinations of the six individual PIEs which were then summed.
Individual PIEs varied between groups and over the study period, suggesting different drivers of instability at different times and within each population. The combinations varied naturally between subjects just as the symptoms of $\mathrm{Sz}$ vary between patients. For example, it is possible that in two patients with the same summary score, one could have three ED visits and low PDC while the other could have one ED visit, a reduction in outpatient psychiatric visits, low PDC, and a diagnosis for another psychotic behavior. Though they displayed different markers of instability, they 


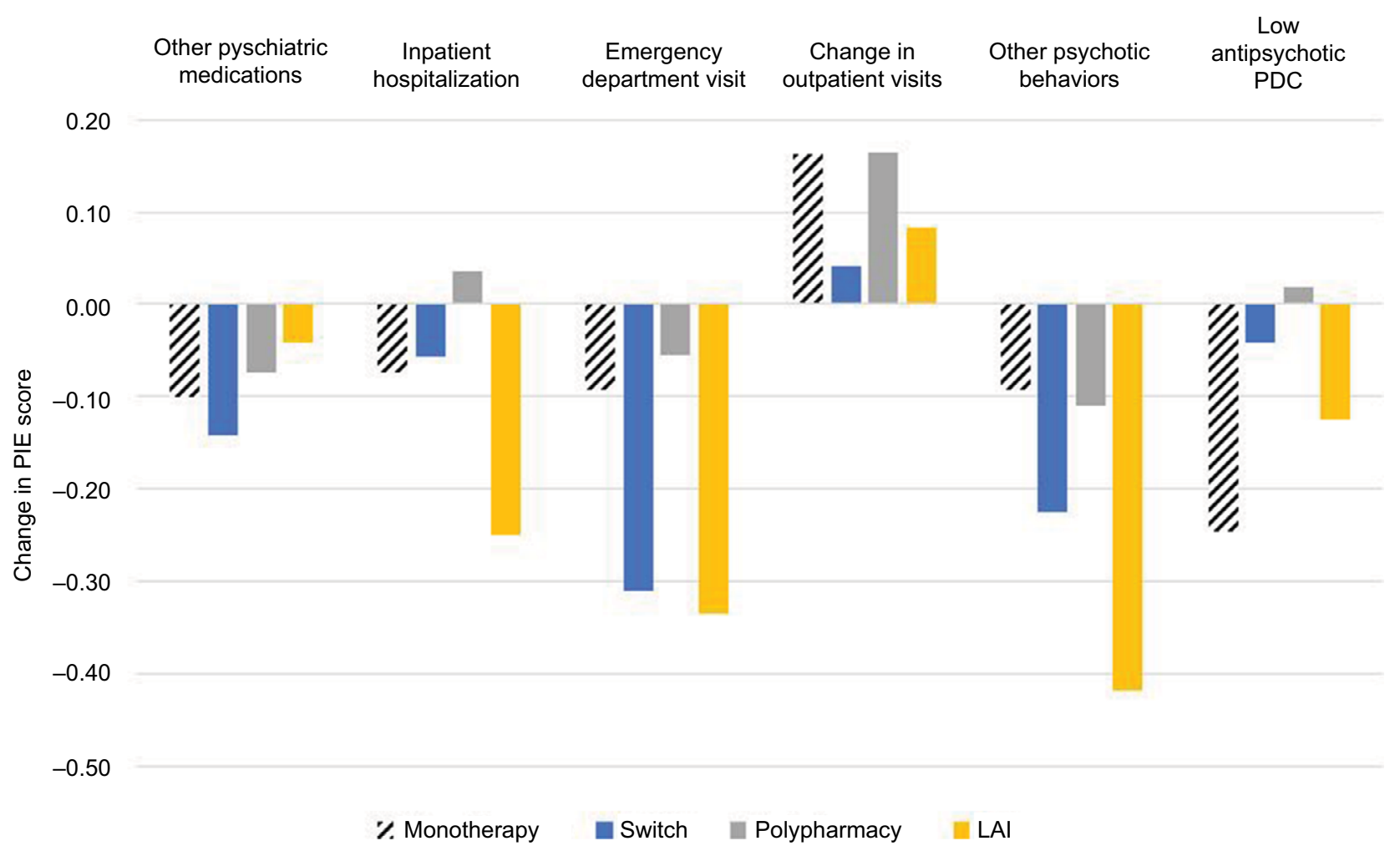

Figure 2 Change in individual PIE scores - Aetna.

Abbreviation: LAI, long-acting injectable; PDC, proportion of days covered; PIE, patient instability event.

have the same summary score. This finding is congruent with the understanding of $\mathrm{Sz}$ as a syndrome or symptoms. Even though no one marker adequately predicts treatment status, ${ }^{31,32}$ the PIE summary score seemed to be a good proxy to quantify the increase in patient instability up to the change in treatment and the decrease in the postperiod following the change. Findings indicated that in addition to the PIE summary score, the individual PIE scores increased in frequency prior to treatment modification, then decreased afterward. This relationship lends indirect support for the PIE summary score as a proxy of instability that is sensitive to both increased instability prior to treatment revision as well as decrease in the same following AP medication adjustment. The association between the PIE summary score and the proxy of patient decompensation (ie, change in treatment regimen) may add support to the use of the PIE summary score as a proxy marker of the same. Assuming that providers may be more likely to change therapies (eg, switch medication, increase dose, etc) at the point of greatest patient instability, the PIE summary score is a reasonable proxy for patient instability.

Within both samples used for this study, the switch and LAI groups exhibited the highest PIE summary scores in both the pre- and postperiods, although the PIEs that drove the summary scores differed among groups and within groups over time. Similarly, although there was an overall decrease in PIEs during the postperiod, the individual PIEs driving the postperiod summary score were different between the two groups and across the study period. In the Aetna sample, the LAI group had the largest decrease in PIE scores during the postperiod while the switch cohort had a higher level of instability in the pre-period but a more modest decline than the LAI group following treatment modification. Though a nonsignificant trend, the steeper decline in PIE summary score for the LAI cohort suggests that the change to an LAI was more effective than switching to a different oral AP for many of the patients in this study. Implementation of rigorous study designs would be necessary to confirm this hypothesis. Both the LAI and switch groups also showed a decrease in ED utilization and inpatient hospitalization following the treatment index date, which may be consistent with improvement following medication change.

The monotherapy group exhibited low levels of instability in the pre-period and modest changes in the postperiod, indicating limited need for a treatment alteration. The decrease in instability during the postperiod for the polypharmacy 
group is somewhat less expected, but not less intuitive. The presence of a second AP may indicate a more severe psychosis, or could simply be used to promote sleep. Though not endorsed by treatment guidelines, ${ }^{33}$ concurrent use of multiple AP medications is nevertheless associated with a reduction of the number of instability events in this study.

In part, these findings support previous studies showing that providers are conservative when modifying pharmaceutical treatment for unstable Sz patients. ${ }^{34}$ In addition, this study supports other findings that prior psychiatric hospitalization and ED visits are part of an instability trajectory to elevated risk of relapse and need for treatment modification. ${ }^{35,36}$ Though not part of this analysis, elevated instability at about the time of the treatment index date may have led to higher rates of rehospitalization had treatment not been modified for the patients in this group. Though not conclusive, the current evidence supports using a simple count of events that indicate some level of instability as a method for tracking disease trajectory leading to elevated risk of relapse.

There are several limitations to this study. First, the sample size within the Aetna claims dataset was small and may have contributed to variability between the Aetna and Truven findings. Second, the analyses were carried out in two commercial claims datasets, but Medicaid and Medicare are the most frequent payers for patients with $\mathrm{Sz}$. Further analysis, especially with increased sample sizes in noncommercial populations, is warranted to increase understanding and assessment of the factors that drive behavioral health management and Sz patient instability. This study also did not assess the relationship between patient instability and direct measures of decompensation (eg, physician Global Assessment of Functioning) or relapse (eg, psychiatric hospitalization), which could be useful in further development of a PIE-based disease management case finding algorithm. Finally, comparison of PIEs based on claims data to a gold standard measure of patient instability or decompensation, such as the Positive and Negative Syndrome Scale, might elucidate the precise nature of claims markers of patient instability.

\section{Conclusion}

Despite these limitations, findings from this study provide support that administrative claims can be used to develop individual and composite measures of instability in patients with Sz. Such measures may provide a viable method to track patient disease trajectories and identify those individuals greatest need of treatment intervention to prevent relapse, improve patient outcomes, and reduce the burden on patients, caregivers, and the health care system.

\section{Acknowledgment}

This study was funded by Otsuka Pharmaceutical Development \& Commercialization, Inc., and Lundbeck LLC. The authors would like to acknowledge Robert Stellhorn for his assistance with the Truven MarketScan analysis.

\section{Disclosure}

Dr Ruetsch works for Health Analytics, LLC an outcomes research organization and has no financial interest in either Aetna or Otsuka, nor any other company that either treats patients with schizophrenia or makes or markets pharmaceuticals for them. Health Analytics was paid by Otsuka to conduct the research. Dr Un is the Chief Psychiatric Officer at Aetna and Dr Waters is the Director, Outcomes Management at Otsuka. The authors report no other conflicts of interest in this work.

\section{References}

1. Mueser KT, McGurk SR. Schizophrenia. Lancet. 2004;363(9426): 2063-2072.

2. Serretti A, Mandelli L, Bajo E, et al. The socio-economical burden of schizophrenia: a simulation of cost-offset of early intervention program in Italy. Eur Psychiatry. 2009;24(1):11-16.

3. Carpenter WT Jr. Schizophrenia: disease, syndrome, or dimensions? Fam Process. 2007;46(2):199-206.

4. Kirkpatrick B, Buchanan RW, Ross DE, Carpenter WT Jr. A separate disease within the syndrome of schizophrenia. Arch Gen Psychiatry. 2001;58(2):165-171.

5. Moller H, von ZD. Course and outcome of schizophrenia. Schizophrenia. Oxford, UK: Blackwell; 1995:127.

6. Subotnik KL, Casaus LR, Ventura J, et al. Long-acting injectable risperidone for relapse prevention and control of breakthrough symptoms after a recent first episode of schizophrenia. A randomized clinical trial. JAMA Psychiatry. 2015;72(8):822-829.

7. Rui Q, Wang Y, Liang S, et al. Relapse prevention study of paliperidone extended-release tablets in Chinese patients with schizophrenia. Prog Neuropsychopharmacol Biol Psychiatry. 2014;53:45-53.

8. Hui CL, Tang JY, Leung CM, et al. A 3-year retrospective cohort study of predictors of relapse in first-episode psychosis in Hong Kong. Aust N Z J Psychiatry. 2013;47(8):746-753.

9. Loebel A, Cucchiaro J, Xu J, Sarma K, Pikalov A, Kane JM. Effectiveness of lurasidone vs. quetiapine XR for relapse prevention in schizophrenia: a 12-month, double-blind, noninferiority study. Schizophr Res. 2013;147(1):95-102.

10. Nicholl D, Akhras KS, Diels J, Schadrack J. Burden of schizophrenia in recently diagnosed patients: healthcare utilisation and cost perspective. Curr Med Res Opin. 2010;26(4):943-955.

11. Lafeuille MH, Gravel J, Lefebvre P, et al. Patterns of relapse and associated cost burden in schizophrenia patients receiving atypical antipsychotics. J Med Econ. 2013;16(11):1290-1299.

12. Talaslahti T, Alanen HM, Hakko H, Isohanni M, Hakkinen U, Leinonen E. Change in antipsychotic usage pattern and risk of relapse in older patients with schizophrenia. Int J Geriatr Psychiatry. 2013;28(12):1305-1311.

13. Emsley R, Chiliza B, Asmal L, Harvey BH. The nature of relapse in schizophrenia. BMC Psychiatry. 2013;13:50.

14. Mokhtari M, Rajarethinam R. Early intervention and the treatment of prodrome in schizophrenia: a review of recent developments. JPsychiatr Pract. 2013;19(5):375-385.

15. Bratlien U, Øie M, Lien L, et al. Social dysfunction in first-episode psychosis and relations to neurocognition, duration of untreated psychosis and clinical symptoms. Psychiatry Res. 2013;207(1-2):33-39. 
16. Addington J, Heinssen R. Prediction and prevention of psychosis in youth at clinical high risk. Annu Rev Clin Psychol. 2012;8(1):269-289.

17. Bouhlel S, Jones Y, Khelifa E, Msolly M, Melki W, El-Hechmi Z. [Prodromal symptoms in schizophrenic relapse: a descriptive and comparative study]. Encephale. 2012;38(5):397-403. French.

18. Barrantes-Vidal N, Gross GM, Sheinbaum T, Mitjavila M, Ballespi S, Kwapil TR. Positive and negative schizotypy are associated with prodromal and schizophrenia-spectrum symptoms. Schizophr Res. 2013;145(1-3): 50-55.

19. Kwapil TR, Gross GM, Silvia PJ, Barrantes-Vidal N. Prediction of psychopathology and functional impairment by positive and negative schizotypy in the Chapmans' ten-year longitudinal study. J Abnorm Psychol. 2013;122(3):807-815.

20. Wu EQ, Birnbaum HG, Shi L, et al. The economic burden of schizophrenia in the United States in 2002. J Clin Psychiatry. 2005;66(9):1122-1129.

21. Almond S, Knapp M, Francois C, Toumi M, Brugha T. Relapse in schizophrenia: costs, clinical outcomes and quality of life. Br JPsychiatry. 2004; 184:346-351.

22. Ascher-Svanum H, Zhu B, Faries D, et al. The cost of relapse and the predictors of relapse in the treatment of schizophrenia. BMC Psychiatry. 2010;10(1):2.

23. Weiden PJ, Olfson M. Cost of relapse in schizophrenia. Schizophr Bull. 1995;21(3):419-429.

24. Fitzgerald P, de Castella A, Arya D, et al. The cost of relapse in schizophrenia and schizoaffective disorder. Australas Psychiatry. 2009;17(4): 265-272.

25. Gaebel W, Riesbeck M. Revisiting the relapse predictive validity of prodromal symptoms in schizophrenia. Schizophr Res. 2007;95(1-3): 19-29.

26. Gleeson JF, Rawlings D, Jackson HJ, McGorry PD. Early warning signs of relapse following a first episode of psychosis. Schizophr Res. 2005;80(1):107-111.
27. Birchwood M, Spencer E. Early intervention in psychotic relapse. Clin Psychol Rev. 2001;21(8):1211-1226.

28. Porcelli S, Bianchini O, De Girolamo G, Aguglia E, Crea L, Serretti A. Clinical factors related to schizophrenia relapse. Int J Psychiatry Clin Pract. 2016;20(2):54-69.

29. Jiang Y, Ni W. Estimating the impact of adherence to and persistence with atypical antipsychotic therapy on health care costs and risk of hospitalization. Pharmacotherapy. 2015;35(9):813-822.

30. Labouvie E, Ruetsch C. Testing for equivalence of measurement scales: simple structure and metric invariance reconsidered. Multivariate Behav Res. 1995;30(1):63-76.

31. Goldstein G, Shemansky WJ. Length and number of hospitalizations in two cohorts of veterans with chronic schizophrenia. Psychiatr Serv. 2000;51(2):245-247.

32. San L, Bernardo M, Gomez A, Martinez P, Gonzalez B, Pena M. Socio-demographic, clinical and treatment characteristics of relapsing schizophrenic patients. Nord J Psychiatry. 2013;67(1):22-29.

33. American Psychiatric Association. Diagnostic and Statistical Manual of Mental Disorders. 4th ed. Washington, D.C., USA: American Psychiatric Association; 2000

34. Sernyak MJ, Dausey D, Desai R, Rosenheck R. Prescribers' nonadherence to treatment guidelines for schizophrenia when prescribing neuroleptics. Psychiatr Serv. 2003;54(2):246-248.

35. Berge D, Mane A, Salgado P, et al. Predictors of relapse and functioning in first-episode psychosis: a two-year follow-up study. Psychiatr Serv. 2016;67(2):227-233.

36. Kim UN, Kim YY, Lee JS. Factors affecting the downward mobility of psychiatric patients: a Korean study of National Health Insurance beneficiaries. J Prev Med Public Health. 2016;49(1):53-60.

37. NICE. Psychosis and Schizophrenia in Adults: Treatment and Management. London, UK: National Institute for Health and Care Excellence; 2014.
ClinicoEconomics and Outcomes Research

\section{Publish your work in this journal}

ClinicoEconomics and Outcomes Research is an international, peerreviewed open-access journal focusing on health technology assessment, pharmacoeconomics and outcomes research in the areas of diagnosis, medical devices, and clinical, surgical and pharmacological intervention. The economic impact of health policy and health systems

\section{Dovepress}

organization also constitute important areas of coverage. The manuscript management system is completely online and includes a very quick and fair peer-review system, which is all easy to use. Visit http://www.dovepress.com/testimonials.php to read real quotes from published authors. 